\title{
Rapid genetic diagnosis with transcription-reverse transcription concerted reaction system for peritoneal recurrence and survival in colorectal cancer patients
}

\author{
TAMURO HAYAMA, HISAE IINUMA and TOSHIAKI WATANABE \\ Department of Surgery, Teikyo University School of Medicine, Tokyo, Japan
}

Received June 7, 2007; Accepted July 16, 2007

\begin{abstract}
The prediction of peritoneal recurrence in colorectal cancer patients is required for improvement of prognosis. In this study, we focused on establishing a novel rapid RNA direct amplification system with transcription-reverse transcription concerted reaction (TRC) to detect carcinoembryonic antigen (CEA) mRNA in peritoneal washings, and its usefulness as a prophylactic tool for peritoneal recurrence and survival in patients with colorectal cancer. Peritoneal washes were obtained from 161 patients with colorectal cancer during laparotomy. CEA mRNA and porphobilinogen deaminase (PBGD) mRNA levels of peritoneal washes were detected using the TRC method. Genetic detection in the CEA mRNA of peritoneal washes by TRC showed a significant correlation to the depth of invasion, lymphatic invasion, venous invasion, lymph node metastasis, peritoneal dissemination and stage. The overall survival and peritoneal recurrence-free survival rates of CEA mRNA-positive patients were significantly poorer than those of marker genenegative patients. CEA mRNA levels in peritoneal washes were a significant independent prognostic factor for overall survival and peritoneal recurrence-free survival. In conclusion, our study demonstrated that the detection of CEA mRNA in peritoneal washings by TRC is a useful, rapid genetic diagnosis for the prediction of peritoneal recurrence and survival in patients with colorectal cancer.
\end{abstract}

Correspondence to: Dr Hisae Iinuma, Department of Surgery, Teikyo University School of Medicine, 2-11-1 Kaga, Itabashi-ku, Tokyo 173-0003, Japan

E-mail: iinuma@med.teikyo-u.ac.jp

Abbreviations: ITC, isolated tumor cells; TRC, transcriptionreverse transcription concerted reaction; RT, reverse transcription; PCR, polymerase chain reaction; CEA, carcinoembryonic antigen; PBGD, porphobilinogen deaminase

Key words: colorectal cancer, peritoneal recurrence, isolated tumor cells, transcription-reverse transcription concerted reaction, peritoneal wash, CEA

\section{Introduction}

Colorectal cancer is the second most common solid organ cancer in developed countries with an incidence worldwide of almost a million cases annually (1). The major prognostic factors of colorectal cancer are metastases to the liver, lymph nodes, and seeding of the peritoneum (2). It was reported that peritoneal seeding is a component of tumor recurrence in 16$36 \%$ of colon cancer patients $(3,4)$. The prognosis of advanced colorectal cancer invading the serosa is very poor, even after curative resection. The presence of isolated tumor cells (ITC) which indicate early peritoneal seeding with subsequent peritoneal metastases is an important prognostic factor and may alter the decision regarding adjuvant chemotherapy in colon cancer patients, as well as in gastric cancer patients (5-9). The detection of ITC in peritoneal washes by cytology has been applied clinically to assess micrometastasis in the peritoneal cavity (6-8); however, conventional cytology lacks sensitivity and it is known that peritoneal recurrence can occur in cytology-negative patients (9-11). Therefore, there is an urgent need for more sensitive methods to detect ITC in the peritoneal cavity.

Accurate inter-operative diagnosis of ITC in the peritoneal cavity is also an important factor for the early application of appropriate adjuvant treatment for peritoneal recurrence. Amplification and detection of molecular markers specific to cancer cells has generally been performed by reverse transcriptase (RT) polymerase chain reaction (PCR) (12-17); however, such procedures are complicated and have multiple steps, including the RT reaction and thermal cycling, and thus take several hours. Therefore, further refinement is required for the clinical application of rapid molecular diagnostic techniques. In this study, we report the application of a novel method of quantitative genetic diagnosis with the transcription reverse transcriptase concerted (TRC) reaction system for the detection of ITC and prediction of cancer recurrence in patients with colorectal cancer (18). This method amplifies and measures cancer-associated messenger RNA (mRNA) such as carcinoembryonic antigen (CEA) in a single tube at a constant temperature without thermal cycling in three steps: denaturing, annealing, and extension for PCR. The reaction at a single temperature may produce stable results and more accurate quantification. Another advantage of this method is that direct RNA amplification is possible, thereby avoiding the need for RT to convert RNA to complementary DNA (cDNA) 
before amplification. This advantage should facilitate rapid diagnosis, which could be applied for intra-operative diagnosis of ITC.

In this study, we introduced the TRC system as a new rapid molecular diagnostic system for the detection of peritoneal ITC in patients with cytology-negative colorectal cancer, and assessed the clinical significance of peritoneal ITC detected by the TRC system for prediction of peritoneal recurrence and survival.

\section{Materials and methods}

Patients and peritoneal lavage specimens. A total of 161 patients with colorectal cancer were studied between 2000 and 2005. The median follow-up period was 22 months (range, 10-48 months). This study was approved by the institutional review board of our hospital, and all patients provided written informed consent. Peritoneal washes collected from 161 patients with colorectal cancer and 15 patients with benign disease were prepared. At the beginning of each operation, $100 \mathrm{ml}$ saline was introduced into the Douglas cavity, and aspirated after gentle stirring. One half of each peritoneal lavage fluid was used for conventional cytopathology and the other half was used for molecular diagnosis. Cells collected from peritoneal washes by centrifugation were rinsed with phosphate-buffered saline (PBS), dissolved in TRIzol RNA extraction buffer (Invitrogen, Carlsbad, CA) and stored at $-80^{\circ} \mathrm{C}$.

TRC reaction. Total cellular RNA was extracted using TRIzol reagent according to the protocol proved by the manufacturer. TRC was measured according to the manufacturer of TRCRtest CEA-m (Tosho Corp.; Kanagawa, Japan). As target gene of colorectal cancer CEA mRNA was selected and porphobilinogen deaminase (PBGD) mRNA was used for housekeeping gene. The synthetic oligonucleotide sequences of a pair of primers, a scissors probe for TRC amplification, and an interaction activating fluorescence (INAF) probe for the detection of CEA mRNA, are as follows: CEA, Promoter primer 5'-AATTCTAATACGACTCACTATAGGGAGAAG CCAGTGGCCACAGCAGGACTA-3', Antisense primer 5'-GTTCACAGGTGAAGGCCACA-3', Scissors probe 5'-CTG GCTG AGTTATTGGCCTGGAG-3', INAF probe 5'-TGCT GGAGATGGAGGGCTTG-3': PBGD, Promoter primer 5'-AATTCTAATACGACTCACTATAGGGAGAACTCC TTGAAGGACCTGCCCACT-3', Antisense primer 5'-GCA GGGTTTCTAGGGTCT-3', Scissors probe 5'-AGGAGTG AACAACCAGGTCCACTT-3', INAF probe 5'-GTGAAG CCAGGAGGAG-3'. In the PCR tube, $20 \mu 1$ of TRC buffer was added to $5 \mu \mathrm{l}$ of the RNA extract, followed by the addition of $5 \mu 1$ of the enzyme mix. The tube containing the mixture was closed and set in a dedicated instrument, the TRC monitor, to measure the fluorescence intensity of the reaction mixture incubated at $44^{\circ} \mathrm{C}$. The TRC buffer contained $90 \mathrm{mM}$ Tris$\mathrm{HCl}, 165 \mathrm{mM} \mathrm{KCl}, 26 \mathrm{mM} \mathrm{MgCl}, 1.5 \mathrm{mM}$ dithiothreitol, $0.38 \mathrm{mM}$ deoxynucleoside triphosphate, $4.5 \mathrm{mM}$ nucleoside triphosphate, $5.4 \mathrm{mM}$ inosine triphosphate, $0.3 \mathrm{U} / \mu 1$ ribonuclease inhibitor, $1.5 \mu \mathrm{M}$ forward primer, $1.5 \mu \mathrm{M}$ reverse primer, $0.24 \mu \mathrm{M}$ scissors probe, $23 \mathrm{nM}$ INAF probe, and $16 \%$ dimethyl sulfoxide. The enzyme mixture consisted

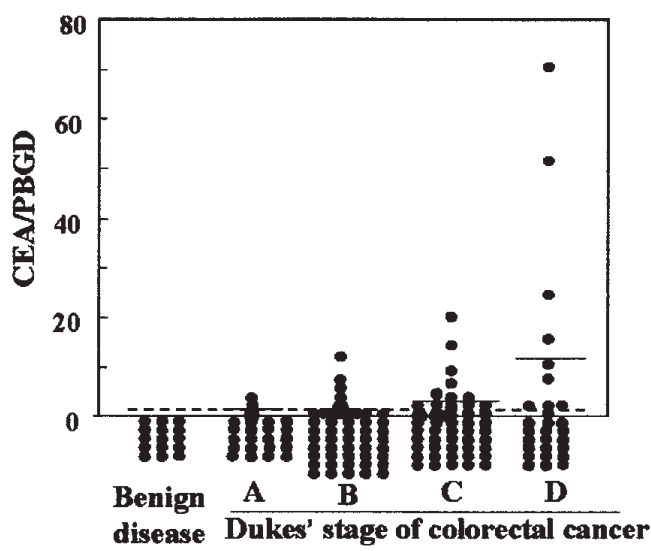

Figure 1. CEA/PBGD levels of benign disease patients and colorectal cancer patients. The levels of CEA/PBGD of benign disease patients and colorectal cancer patients with Dukes' stage A, B, C or D are shown. CEA/PBGD levels were increased according to the tumor stage. The dotted line shows the cut-off level of CEA/PBGD (0.08). The solid line shows the average of CEA/PBGD in each Dukes' stage. (Dukes' A, 0.29; Dukes' B, 0.58; Dukes' C, 1.76; Dukes' D, 12.21).

of $0.72 \mathrm{mg} / \mathrm{ml}$ bovine serum albumin, $12 \%$ sorbitol, $1.3 \mathrm{U} / \mu 1$ AMV RT (Takara, Kyoto, Japan), and 34 U/ $\mu 1$ T7 RNA polymerase (Life Technologies, Gaithersburg, MD). The TRC reaction was monitored using a round incubator block and a rotating fluorescence scanning unit. The temperature of the incubator block was controlled at $44^{\circ} \mathrm{C}$, and 32 thinwalled PCR tubes were installed and set in a circle. They were assembled into one unit to enable synchronous scanning of the fluorescence while the tube was irradiated. The lightemitting diode turns like a beacon to irradiate the excitation light $(470 \mathrm{~nm})$ into a tube from the outside. The fluorescence $(520 \mathrm{~nm})$ is transferred from the bottom of the tube to a photomultiplier through a light guide. All samples were measured in duplicate. The mRNA in each sample was quantified automatically with reference to the standard curve of the positive control, according to TRC software. The levels of CEA mRNA were normalized by PBGD mRNA, and the ratio of CEA copies to the PBGD copies (CEA/ PBGD) was calculated.

Postoperative surveillance. The follow-up program, consisting of interim history, physical examination, hematology and blood chemistry, was performed every 3 months for the first operative year and every 6 months thereafter. Computed tomography or abdominal ultrasonography were examined every 6 months. Evidence of peritoneal recurrence was diagnosed comprehensively with parameters including paracentesis and autopsy.

Statistical analysis. Overall survival and peritoneal recurrencefree survival were analyzed using the Kaplan-Meier method. Univariate and multivariate analysis were performed using Cox regression analyses. $\mathrm{P}<0.05$ was considered statistically significant.

\section{Results}

Expression of CEA mRNA in benign disease patients and colorectal cancer patients. The CEA mRNA values normalized 
Table I. Relationship between CEA mRNA-positive rates of peritoneal washes and clinicopathological factors.

\begin{tabular}{|c|c|c|c|c|}
\hline Variables & $\begin{array}{c}\text { Number of } \\
\text { patients }(n=161)\end{array}$ & $\begin{array}{l}\text { PCR positive } \\
\quad(n=32)\end{array}$ & $\begin{array}{l}\text { Positive } \\
\text { rate }(\%)\end{array}$ & P-value \\
\hline \multicolumn{5}{|c|}{ Tumor size (cm) } \\
\hline$<5$ & 93 & 16 & 17.2 & \multirow[t]{2}{*}{0.322} \\
\hline$\geq 5$ & 68 & 16 & 23.5 & \\
\hline \multicolumn{5}{|c|}{ Histological type } \\
\hline Wel & 118 & 23 & 19.5 & \multirow[t]{3}{*}{0.107} \\
\hline Mod & 29 & 7 & 24.1 & \\
\hline Por, Muc & 14 & 2 & 14.3 & \\
\hline \multicolumn{5}{|c|}{ Depth of invasion } \\
\hline$\leq \mathrm{mp}$ & 83 & 8 & 9.6 & \multirow[t]{2}{*}{$<0.001$} \\
\hline$\geq \operatorname{ss}(\mathrm{al})$ & 78 & 24 & 30.8 & \\
\hline \multicolumn{5}{|c|}{ Lymphatic invasion } \\
\hline ly (-) & 110 & 14 & 12.7 & \multirow[t]{2}{*}{0.001} \\
\hline ly $(+)$ & 51 & 18 & 35.3 & \\
\hline \multicolumn{5}{|c|}{ Venous invasion } \\
\hline $\mathrm{v}(-)$ & 64 & 7 & 10.9 & \multirow[t]{2}{*}{0.017} \\
\hline $\mathrm{v}(+)$ & 97 & 25 & 25.8 & \\
\hline \multicolumn{5}{|c|}{ Lymph node metastasis } \\
\hline $\mathrm{n}(-)$ & 91 & 8 & 8.8 & \multirow[t]{2}{*}{$<0.001$} \\
\hline $\mathrm{n}(+)$ & 70 & 24 & 34.3 & \\
\hline \multicolumn{5}{|c|}{ Liver metastasis } \\
\hline H (-) & 143 & 27 & 18.9 & \multirow[t]{2}{*}{0.373} \\
\hline $\mathrm{H}(+)$ & 18 & 5 & 27.8 & \\
\hline \multicolumn{5}{|c|}{ Peritoneal dissemination } \\
\hline $\mathrm{P}(-)$ & 158 & 30 & 19.0 & \multirow[t]{2}{*}{0.040} \\
\hline $\mathrm{P}(+)$ & 3 & 2 & 66.7 & \\
\hline \multicolumn{5}{|l|}{ Dukes' stage } \\
\hline A & 24 & 2 & 8.3 & \multirow[t]{4}{*}{0.007} \\
\hline B & 59 & 6 & 10.2 & \\
\hline $\mathrm{C}$ & 51 & 15 & 29.4 & \\
\hline $\mathrm{D}$ & 27 & 9 & 33.3 & \\
\hline
\end{tabular}

with PBGD mRNA levels (CEA/PBGD) in the peritoneal washings of 15 patients with benign diseases were examined to determine the cut-off levels (Fig. 1). As cut-off values, we determined 0.08 , which is the $95 \%$ confidence interval (mean plus 1.96 standard deviation) of benign disease patients. Average of CEA/PBGD levels in each Dukes' stage were 0.29 in Dukes' A, 0.58 in Dukes' B, 1.76 in Dukes' C and 12.12 in Dukes' D. CEA/PBGD levels of colorectal cancer patients were increased according to the progression of tumor stage.

Relationship between CEA mRNA and clinicopathological factors. The relationship between CEA mRNA positive rates in peritoneal washes and the clinicopathological factors were examined (Table I). A significant relationship was demonstrated between positivity for CEA mRNA and depth of tumor invasion, lymphatic invasion, venous invasion, lymph node metastasis, peritoneal dissemination and stage. These results suggest that the presence of ITC in the peritoneal washings correlated to parameters associated with tumor progression.

Correlation between survival and CEA mRNA. Kaplan-Meier survival curves of cytology-negative patients were examined between CEA mRNA-positive patients and CEA mRNAnegative patients. The overall survival of CEA mRNA-positive patients showed a significantly poorer prognosis than that of CEA mRNA-negative patients (Fig. 2). Peritoneal recurrencefree survival was analyzed for patients with curative resection. In this analysis, patients who were CEA mRNA-positive showed a significantly poorer prognosis than patients who were CEA mRNA-negative (Fig. 3). These results suggest 


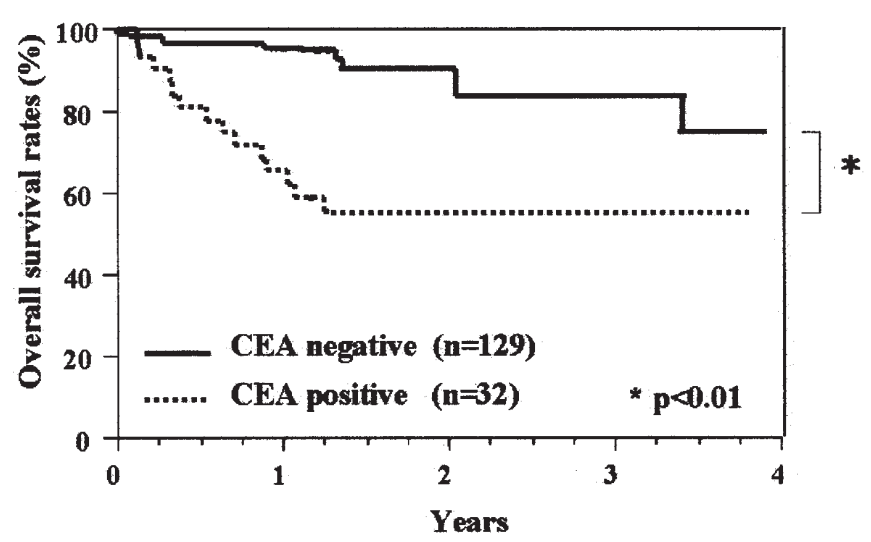

Figure 2. Overall survival analysis based on CEA mRNA in peritoneal washings. Overall survival rates for 161 patients were analyzed by the Kaplan-Meier method, and significant difference was shown between CEApositive and CEA-negative groups.

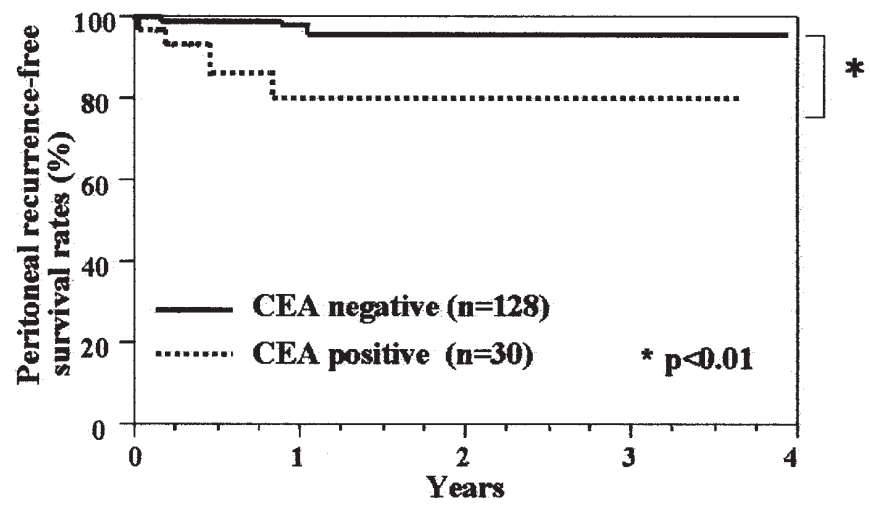

Figure 3. Peritoneal recurrence-free survival analysis based on CEA mRNA in peritoneal washings. Peritoneal recurrence-free survival curves for 158 curative patients were analyzed by the Kaplan-Meier method, and significant difference was shown between CEA-positive and CEA-negative groups.

that CEA mRNA of peritoneal washings by TRC could be a useful prognostic indicator for survival.

Univariate and multivariate analysis of prognostic factors. Tables II and III show univariate and multivariate Cox proportional hazard regression analysis for overall survival and peritoneal recurrence-free survival. In univariate analyses, significant relationships were shown concerning lymph node metastasis, lymphatic invasion, venous invasion and CEA mRNA. Multivariate analyses were then performed for factors that showed significance in univariate analyses, and CEA mRNA showed significance for overall survival and peritoneal recurrence-free survival. These results suggested that CEA mRNA in peritoneal washes possesses an independent prognostic value for overall survival and peritoneal recurrencefree survival.

\section{Discussion}

Using the new rapid TRC system, we demonstrated that the detection of CEA mRNA in peritoneal washings of
Table II. Univariate and multivariate analysis for the prediction of overall survival.

\begin{tabular}{|c|c|c|c|c|c|c|}
\hline \multirow[t]{2}{*}{ Variables } & \multicolumn{3}{|c|}{ Univariate analysis } & \multicolumn{3}{|c|}{ Multivariate analysis } \\
\hline & $\mathrm{RC}^{\mathrm{a}}$ & $\begin{array}{l}\text { Hazard } \\
\text { ratio }\end{array}$ & $\mathrm{P}$ & $\mathrm{RC}$ & $\begin{array}{l}\text { Hazard } \\
\text { ratio }\end{array}$ & $\mathrm{P}$ \\
\hline CEA mRNA & 1.15 & 3.17 & 0.01 & 0.68 & 1.98 & 0.02 \\
\hline $\begin{array}{l}\text { Lymph node } \\
\text { metastasis }\end{array}$ & 1.20 & 3.33 & 0.01 & -0.63 & 0.54 & 0.07 \\
\hline Lympatic invasion & 0.79 & 2.19 & 0.02 & -0.01 & 0.99 & 0.98 \\
\hline Venous invasion & 0.86 & 2.37 & 0.04 & 0.39 & 1.47 & 0.20 \\
\hline
\end{tabular}

${ }^{\mathrm{a} R C}$, regression coefficient.

Table III. Univariate and multivariate analysis of prognostic factors in peritoneal recurrence-free survival.

\begin{tabular}{lcccccccc}
\hline Variables & \multicolumn{3}{c}{ Univariate analysis } & & \multicolumn{3}{c}{ Multivariate analysis } \\
\cline { 2 - 3 } & & $\mathrm{RC}^{\mathrm{a}}$ & $\begin{array}{c}\text { Hazard } \\
\text { ratio }\end{array}$ & $\mathrm{P}$ & & $\mathrm{RC}$ & $\begin{array}{c}\text { Hazard } \\
\text { ratio }\end{array}$ & $\mathrm{P}$ \\
\hline CEA mRNA & 0.85 & 2.33 & 0.01 & 0.84 & 2.31 & 0.02 \\
$\begin{array}{l}\text { Lymph node } \\
\text { metastasis }\end{array}$ & 0.86 & 2.36 & 0.01 & 0.77 & 2.16 & 0.13 \\
Lympatic invasion & 0.42 & 1.52 & 0.03 & 0.27 & 1.31 & 0.48 \\
Venous invasion & 0.89 & 2.42 & 0.01 & 0.26 & 1.29 & 0.65 \\
\hline
\end{tabular}

${ }^{\mathrm{a} R C}$, regression coefficient.

cytology-negative colorectal cancer patients is an independent predictive factor for overall and peritoneal recurrence-free survival.

Micrometastasis, defined as invisible metastasis missed by conventional microscopic examination, is considered to be of great clinical significance in the field of oncology $(19,20)$. A significant relationship between the ITC of peritoneal washings and micrometastasis of the peritoneum has been demonstrated (6-8). Molecular diagnosis based on PCR is a powerful tool for the detection of ITC of peritoneal washings. Several studies have reported the usefulness of the molecular detection of ITC by real-time RT-PCR as a prognostic factor (12-23). In colorectal and gastric patients, many studies have demonstrated that the prognosis of ITC-positive patients in peritoneal washings is significantly poorer than that of ITC-negative patients $(14,15,19,21)$. Furthermore, it was thought that intraoperative rapid genetic diagnosis of peritoneal washings is important for the early start of adjuvant chemotherapy and improvement of prognosis. Mori et al reported that intraperitoneal chemotherapy could improve the prognosis of gastric cancer patients with RT-PCR-positive in peritoneal 
lavage fluid (22). Marutsuka et al suggested the significance of complete washing of the peritoneal cavity in patients with RT-PCR positive peritoneal fluid (23).

However, PCR-based methods have several engineering obstacles that must be overcome before they can be applied in the clinical setting as intra-operative genetic diagnosis. PCR-based detection of cancer-specific genes requires an RT step after RNA extraction. Furthermore, PCR requires more than 35 cycles of 3 steps at different incubation temperatures, which is all time consuming. It is known that real-time RTPCR by LightCycler format, which use a glass capillary for amplification of transcripts, is the fastest in a real-time RT-PCR system. Several studies have applied this LightCycler format for the genetic detection of micrometastasis in peritoneal lavage fluids and lymph nodes (13-15,21-25). However, for amplification of the target gene, one-step real-time RT-PCR using the LightCycler format takes $\sim 70 \mathrm{~min}$, while two-step real-time RT-PCR takes $\sim 90 \mathrm{~min}$. In contrast, the TRC method used in this study is a novel rapid RNA direct amplification system $(17,18)$. The TRC method is based on amplification of the isothermal RNA sequence in the presence of INAF DNA probe and measurement of the fluorescence intensity of the reaction mixture. The progress of amplicon production can be monitored in real-time by measuring the fluorescence intensity of the reaction mixture. After RNA extraction, the TRC reaction is completed in only $20 \mathrm{~min}$. The rapidity and simplicity of the TRC technique is superior to the RT-PCR format, and intra-operative predictive diagnosis of peritoneal recurrence becomes possible with the TRC system.

With regards to the clinical significance of the molecular diagnosis of ITC in peritoneal washings, most studies of patients with gastric cancer have demonstrated the predictive usefulness of molecular markers. In contrast, molecular detection of ITC in peritoneal washings of colorectal cancer patients has not been studied in great detail. Using real-time RT-PCR by way of the ABI Prism 7700 format, it was reported that the detection of CEA and CK20 mRNA in blood and peritoneal washings has prognostic relevance in patients undergoing curative resection of colorectal cancer (19). In this study, we used a new rapid TRC system for real-time quantification of CEA mRNA in peritoneal samples of colon cancer patients and examined the relationship between the clinicopathological factors and prognosis. Concerning the relationship between CEA mRNA of peritoneal washes and clinicopathological factors, we demonstrated a significant relationship between the CEA mRNA and depth of tumor invasion, lymphatic invasion, venous invasion, lymph node metastasis, peritoneum dissemination and stage. We then evaluated the prognostic value of CEA mRNA in peritoneal washes and showed that Kaplan-Meier survival curves of overall and peritoneal recurrence-free survival were significantly poorer in CEA mRNA-positive patients than in cases negative for these marker genes. Furthermore, Cox multivariate analysis has shown that CEA mRNA in peritoneal washes was an independent prognostic factor for survival. Guller et al demonstrated that detection of CEA and/or CK20 mRNA of peritoneal washes has potential clinical utility as a prognostic marker in colorectal cancer patients with curative resection (19). Using the immunobead RT-PCR method, Lloyd et al reported that the molecular detection of ITC in peritoneal fluid is useful as a prognostic factor (20). To our knowledge, this is the first study to demonstrate the prognostic value of CEA mRNA in peritoneal washes of colon cancer patients using the TRC method.

In conclusion, we demonstrated that CEA mRNA detection with the TRC system is a useful tool for rapid intra-operative molecular diagnosis in screening for patients at high risk for peritoneal recurrence. Patients with CEA mRNA-positive results in peritoneal washes may require complete washing of the peritoneal cavity and adjuvant chemotherapy.

\section{Acknowledgements}

We are grateful to T. Takada and Dr K. Okinaga for their comments and thank Ms. J. Tamura for her excellent technical support. This study was supported in part by a Grantin-Aid for Cancer Research (17-15) from the Ministry of Health, Labor and Welfare.

\section{References}

1. Weitz J, Koch M, Debus J, Hohler T, Galle PR and Bucler MW: Colorectal cancer. Lancet 465: 153-165, 2005.

2. Yamaguchi A, Tsukioka Y, Fushida S, Kurosaka Y, Kanno M, Yonemura Y, Miwa K and Miyazaki I: Intraperitoneal hyperthermic treatment for peritoneal dissemination of colorectal cancers. Dis Colon Rectum 35: 964-968, 1992.

3. Safi F and Beyer HG: The value of follow-up after curative surgery of colorectal carcinoma. Cancer Detect Prev 17: 417-424, 1993

4. Travellas G, Patel H and Allen-Mersh TG: Detection and clinical significance of occult tumor cells in colorectal cancer. Br J Surg 88: 1307-1320, 2001.

5. Liefers GJ, Cleton-Jansen AM, van de Velde CJ, Hermans J, van Krieken JH, Cornrlisse CJ and Tollenaar RA: Micrometastases and survival in stage II colorectal cancer. N Engl J Med 339: 223-228, 1998.

6. Zeng Z, Cohen AM, Hajdu S, Stemberg SS, Sigurdson ER and Enker W: Serosal cytologic study to determine free mesothelial penetration of intraperitoneal colon cancer. Cancer 70: 737-740, 1992.

7. Hase K, Ueno H, Kuranaga N, Utsunomiya K, Kanabe S and Mochizuki H: Intraperitoneal exfoliated cancer cells in patients with colorectal cancer. Dis Colon Rectum 41: 1134-1140, 1998.

8. Bonenkamp JJ, Songun I, Hermans J and Velde CJH: Prognostic value of positive cytology findings from abdominal washings in patients with gastric cancer. Br J Surg 83: 672-674,1996.

9. Hayes N, Wayaman J, Wadehara V, Scott DJ, Raimes SA and Griffin SM: Peritoneal cytology in the surgical evaluation of gastric carcinoma. Br J Cancer 79: 520-524, 1991.

10. Abe S, Yoshiwara H, Tabata H, Tachibana M, Monden N, Nakamura T and Nagaoka S: Curative resection of gastric cancer: limitation of peritoneal lavage cytolology in predicating the outcome. J Surg Oncol 59: 226-229,1995.

11. Schott A, Vogel I, Krueger U, Kalthoff H, Schreiber HW, Schmiegel W, Henne-Bruns D, Kremer B and Juhl H: Isolated tumor cells are frequently detectable in the peritoneal cavity of gastric and colorectal cancer patients and serve as a new prognostic marker. Ann Surg 227: 372-379, 1998.

12. Oyama K, Terashima M, Takagane A and Maesawa C: Prognostic significance of peritoneal minimal residual disease in gastric cancer detected by reverse transcription-polymerase chain reaction. Br J Cancer 91: 435-443, 2004.

13. Iinuma H, Okinaga K, Egami H, Mimori K, Hayashi N, Nishida K, Adachi M, Mori M and Sasako M: Usefulness and clinical significance of quantitative real-time RT-PCR to detect isolated tumor cells in the peritoneal blood and tumor drainage blood of patients with colorectal cancer. Int J Oncol 28: 297-306, 2006.

14. Nakanishi H, Kodera Y, Yamamura Y, Ito S, Kato T, Ezaki T and Tatematsu M: Rapid quantitative detection of carcinoembryonic antigen-expressing free tumor cells in the peritoneal cavity of gastric cancer patients with real-time RT-PCR on the lightcycler. Int J Cancer Pediat Oncol 89: 411-417, 2000. 
15. Kodera Y, Nakanishi H, Ito S, Yamamura Y, Kanemitsu Y, Simizu Y, Hirai T, Yasui K, Kato T and Tatematsu M: Quantitative detection of disseminated free cancer cells in peritoneal washes with real-time reverse transcriptasepolymerase chain reaction. Ann Surg 235: 499-506, 2002.

16. Mori K, Aoyagi K, Udea T, Danjoh I, Tsubosa Y, Yanagihara K, Matsuno Y, Sasako M, Sakamoto H, Mafune K, Kaminishi M, Yoshida T, Tarada M and Sasaki H: Highly specific marker genes for detecting minimal gastoric cancer cells in cytology negative peritoneal washings. Biochem Biophys Res Commun 313: 931-937, 2004

17. Ishii T, Fujiwara Y, Ohnaka S, Hayashi T, Taniguchi H, Takiguchi S, Yasuda T, Yano M and Monden M: Rapid genetic diagnosis with the transcription-reverse transcription concerted reaction system for cancer micrometastasis. Ann Surg Oncol 11: 778-785, 2004.

18. Ishiguro T, Saitoh $\mathrm{J}$ and Horie R: Intercalation activating fluorescence DNA probe and its application to homogeneous quantification of a target sequence by isothermal sequence amplification in a closed vessel. Anal Biochem 314: 77-86, 2003.

19. Guller U, Zajac P, Schnider A, Bosch B, Vorburger S, Zuber M, Spagnoli GC, Oertli DC, Maurer R, Metzger U, Harder F, Heberer M and Marti R: Disseminated single tumor cells as detected by real-time quantitative polymerase chain reaction represent a prognostic factor in patients undergoing surgery for colorectal cancer. Ann Surg 236: 768-776, 2002.

20. Lloyd JM, McIver CM, Sephenson SA, Hewett PJ, Rieger N and Hardinghm JE: Identification of early-stage colorectal cancer patients at risk of relapse post-resection by immunobead reverse transcription-PCR analysis of peritoneal lavage fluid of malignant cells. Clin Cancer Res 12: 417-423, 2006.
21. Tamura N, Iinuma $\mathrm{H}$ and Takada T: Prospective study of quantitative CEA and CK20 mRNA detection in peritoneal washes to predict peritoneal recurrence in gastric carcinoma patients. Oncol Rep 17: 667-672, 2007.

22. Mori T, Fujiwara Y, Sugita Y, Azama T, Ishii T, Taniguchi K, Yamazaki K, Takiguchi S, Yasuda T, Yano M and Monden M: Application of molecular diagnosis for detection of peritoneal micrometastasis and evaluation of preoperative chemotherapy in advanced gastric carcinoma. Ann Surg Oncol 11: 14-20, 2004.

23. Marutsuka T, Shimada S, Shiomori K, Hayashi N, Yagi Y, Yamane $\mathrm{T}$ and Ogawa M: Mechanism of peritoneal metastasis after operation for non-serosa-invasive gastric carcinoma: an ultra rapid detection system for intraperitoneal free cancer cells and a prophylactic strategy for peritoneal metastasis. Clin Cancer Res 9: 678-685, 2003.

24. Miyake Y, Fujiwara Y, Ohue M, Yamamoto H, Sugita Y, Tomita N, Sekimoto M, Shiozaki H and Monden M: Quantification of micrometastasis in lymph nodes of colorectal cancer using real-time fluorescence polymerase chian reaction. Int $\mathbf{J}$ Oncol 16: 289-293, 2000.

25. Kubota K, Nakanishi H, Hiki N, Shimizu N, Tsuji E, Yamaguchi $\mathrm{H}$, Mafune $\mathrm{K}$, Tange $\mathrm{T}$, Tatematsu $\mathrm{M}$ and Kaminishi M: Quantitative detection of micrometastases in the lymph nodes of gastric cance patients with real-time RT-PCR: a somparative study with immunochemistry. Int J Cancer 105: 136-143, 2003. 